\title{
RELÍQUIAS DA FARINHADA NA XILOGRAVURA DE JOSÉ COSTA LEITE RELIQUIAS DE LA FARINHADA EN LA XILOGRAVURA DE JOSÉ COSTA LEITE
}

\author{
Márcia Ferreira de Carvalho \\ Universidade Federal da Paraíba-UFPB \\ mardemarcia@yahoo.com.br
}

Resumo: Este trabalho tem como objetivo analisar, com base na teoria semiótica, a xilogravura "A Farinhada", de autoria do poeta e xilogravador José Costa Leite, paraibano, nascido em Sapé, em 1927. Hoje reside em Condado-PE, numa região fronteiriça entre os dois Estados, razão pela qual o governo de Pernambuco também o incluiu no Patrimônio imaterial de seu Estado. A fundamentação teórica desse estudo consiste nos postulados de Greimas, Rastier, Pais e Batista. Nessa análise, identificamos os valores dos sujeitos, as relações intersubjetivas dos enunciados, os procedimentos discursivos de tematização e figurativização, além do inserimento dos atores em zonas antrópicas. Por fim, encontramos cinco sujeitos semióticos, a tensão dialética entre artesanal/industrial e um enunciador distante no tempo e no espaço narrado.

PALAVRAS-CHAVE: Xilogravura; Semiótica; Texto Popular.

Resumen. Este trabajo tiene como objetivo analizar, con base en la teoría semiótica, la xilografía "A Farinhada", de autoría del poeta y xilograbador José Costa Leite, paraibano, nacido en Sapé, en 1927. Hoy reside en Condado-PE, en una región fronteriza entre los dos Estados, razón por la cual el gobierno de Pernambuco también lo incluyó en el Patrimonio inmaterial de su Estado. La fundamentación teórica de este estudio consiste en los postulados de Greimas, Rastier, Pais y Batista. En este análisis, identificamos los valores de los sujetos, las relaciones intersubjetivas de los enunciados, los procedimientos discursivos de tematización y figurativización, además del inserción de los actores en zonas antrópicas. Por último, encontramos cinco sujetos semióticos, la tensión dialéctica entre artesanal / industrial y un enunciador distante en el tiempo y en el espacio narrado.

PALABRAS CLAVE: Xilografía; semiótica; Texto Popular.

\section{Análise semiótica da xilogravura A farinhada}

Apresentando apenas duas cores (preta e branca) e medindo 17x22 centímetros, a obra em análise retrata uma das mais expressivas tradições culturais do interior nordestino, a farinhada, o momento da transformação da mandioca em farinha, alimentação típica e necessária do povo nordestino.

A narrativa se constrói com um percurso constituído de cinco sujeitos semióticos: o sujeito semiótico $1(\mathrm{~S} 1)$ é figurativizado por uma mulher baixa e branca, que se instaura como um sujeito de um dever descascar a mandioca. Ela está sentada e apresenta sinais de cansaço, apoiando-se na gamela ${ }^{1}$, uma vez que esse trabalho é cansativo e demorado. À direita deste sujeito, há um outro, o S2 que é representado

\footnotetext{
1 Vasilha de madeira ou de barro, com a forma de alguidar ou de escudela grande, usada para lavagens ou para dar comida aos animais domésticos. (FERREIRA, 1986, p. 833)
} 
pela cevadeira ${ }^{2}$, que se encontra em pé, destacada pela roupa composta e elegante, postura firme e tem o papel mais elevado: deve fazer o abastecimento da máquina trituradora, com mandiocas inteiras descascadas, no processo artesanal de trituração dessas raízes. Essas mulheres desempenham funções que exigem paciência e jeito, tanto pelo favorecimento da boa qualidade do produto, quanto pelo cuidado para evitar acidentes, dada a rusticidade da máquina, movida por dois atores que estão em pé, um de cada lado do caititu ${ }^{3}$, e constituem os sujeitos semióticos S3 e S4 que executam o dever mais pesado de toda essa sessão: puxar a roda para que o caititu triture as raízes de mandioca. Feito isso, chegamos ao momento, no qual a massa vai para uma prensa, sem aparente indicação de sujeito para acioná-la. Ela se encontra acima dos dois homens e tem a função de separar a parte líquida da sólida. A primeira parte é despejada em um balde que recebe o líquido escorrido da prensa e se encontra atrás dos atores que impulsionam o caititu. A parte sólida vai para um grande deposito que se encontra no alto à esquerda da prensa, bem ao lado do sujeito semiótico 5 (S5), cujo objeto de valor é torrar a farinha: com a mão, ele tira a massa que está no caçuá (balaio de cipó trançado) e coloca-a no forno de barro e a mexe com uma grande colher de pau com os dois braços para não deixá-la queimar. Este é um homem atento e conhecedor do momento em que a farinha fica pronta para ser consumida. Além do mais, esse sujeito goza do privilégio de ser reconhecido pelas delícias que fabrica (pé-de-moleque, beiju, tapioca, sequilho, cocorote e outros derivados da mandioca) que são assadas junto com a farinha de mandioca. O último momento desse processo constitui a confecção dos sacos de farinha que é figurativizado nos sacos de farinha prontos para serem distribuídos para venda e consumidos.

Vale dizer que todo esse processo representa o tema trabalho, numa concepção que ratifica o dito popular de que "a união faz a força". Aliás, a união aqui é um outro tema, figurativizado nas atividades conexas e contíguas, desde o plantio da mandioca, o trato, a colheita, a seleção, o transporte, a raspagem ou descascamento, o abastecimento da máquina, a movimentação da roda, a prensagem da massa, o aproveitamento da goma e da manipueira ${ }^{4}$, a torrefação da farinha e demais derivados, a embalagem em

\footnotetext{
${ }^{2}$ objeto cilíndrico provido de lâminas de metal, que reduz as raízes a pedaços mais ou menos finos; essas lascas são recolhidas por uma gamela ou cocho, feito de um simples tronco de madeira cavado, colocado próximo aos pés da pessoa, geralmente mulher, que "ceva" as raízes

${ }^{3}$ Peça principal do aparelho de ralar mandioca: cilindro de madeira ao longo do qual se adaptam serrilhas metálicas com uma das extremidades, conformada em roldana de gorne para a passagem da correia ou corda que imprime a rotação; rodete. (FERREIRA, 1986, p.314)

${ }^{4}$ Líquido venenoso da mandioca
} 
sacos maiores para a venda em grosso e em menores depósitos para a venda a varejo. A limpeza dos utensílios em geral e, por fim, a preparação do local, chamado popularmente de casa de farinha, para outras farinhadas, constitui a etapa pressuposta no texto.

Em seus traços estratégicos, essa xilogravura põe os cenários em seus respectivos lugares, de modo que o enunciatário (sujeito observador) adentra-se com o olhar em cada um dos compartimentos onde são desenvolvidas essas atividades. Por exemplo, o ator raspadeira está colocado no primeiro plano, permitindo ser visto o mais próximo possível do enunciatário, graças às linhas definidoras de sua cabeça que estabelecem domínio de continuidade sobre a parte inferior da cia (corda resistente que possibilita o movimento do caititu ) que faz ralar a mandioca, a partir do movimento da roda. Esta, com a máquina trituradora e a servadeira formam o segundo plano, considerando que a parte superior da cia projeta-se sobre os sacos de farinha empilhados num terceiro plano; o caititu, com parte da base encoberta pelos sacos, alinha-se com o forno e o torrador de farinha que está junto do caçuá de onde tira a massa de mandioca, encontrando-se em um quarto plano e, assim sucessivamente.

Mais uma vez, sendo uma obra de arte, temos um enunciador narrador e, portanto, distante, no tempo e no espaço, do enunciado narrado. No entanto, no enunciado, existe um procedimento de actorialização, constituído de atores referidos pelos papéis temáticos que exercem (papéis sociais) homens e mulheres, descascadeira, cevadeira, torrador e prensador, etc). Eles se encontram em uma zona antrópica de identidade/proximidade e, como tal, os objetos transacionais, que utilizam nas relações estabelecidas entre eles, são fetiches: cia, gamela, caititu, balde, prensa, balaio, colher de pau, sacos de farinha, mandioca que levam à compreensão do que está se fabricando: a farinha.

No espaço, casa de farinha, há mais homens que mulheres, no entanto, as mulheres desempenham as atividades que exigem mais habilidades/especialidade manuais para se alcançar êxito na finalização do trabalho. Em outras palavras, não seria possível produzir esse alimento sem que a mandioca fosse descascada e colocada no caititu pelas mãos ágeis da mulher que as desempenha com muito mais habilidade que os homens.

Não existe indicação precisa do tempo, uma vez que a farinhada é feita, na xilogravura, de forma artesanal e, pressupõe uma fase anterior à chegada da industrialização, ou seja, anterior ao início da segunda metade do século vinte. Não é 
preciso ir tão longe para se perceber a ausência de instalação elétrica nessa casa de farinha, movida pela força humana no processo de integração de determinada comunidade. Vale dizer que na atualidade esse processo está em quase total extinção, devido à substituição de máquinas elétricas com produção em larga escala, cujo valor maior é o lucro.

Percebemos ainda que a ação representada nessa xilogravura está ocorrendo em pleno dia, entendimento este fundamentado na ausência de portadores de luz (lamparina, candeeiro, vela etc), restando apenas a luz do dia que permite a execução das atividades.

Esse processo manual de produção de alimentos, desenvolvido tipicamente no interior nordestino, caiu em desuso, perdendo espaço para as sofisticadas máquinas elétricas. De acordo com Lyra (1979, p.25), essa evolução ocorrida nos aviamentos ${ }^{5}$ da farinhada classifica-se em três modelos: artesanal, semi-artesanal e moto-mecanizada. Dentre essa classificação, a xilogravura em análise classifica-se como casa de farinha artesanal, uma vez que, ao invés do motor, funciona uma roda movida pela força física do próprio homem. Em oposição a essa cultura artesanal, a industrializada, apesar de permitir velocidade na quantidade da produção, perde em qualidade e em transcendência intercultural, uma vez que essa forma irá se processar no lucro que se centraliza em um único dono que compra a mão de obra dos operários e com isso nega a transação solidária entre pessoas e famílias. Esse regime faz com que haja um isolamento cultural sem união e sem força, onde se quer são garantidos os respectivos direitos trabalhistas a essas pessoas. Tal oposição pode ser representada pelo seguinte octógono:

\footnotetext{
${ }^{5}$ Engenho rústico para fabricar farinha de mandioca (FERREIRA, 1986, p.207)
} 


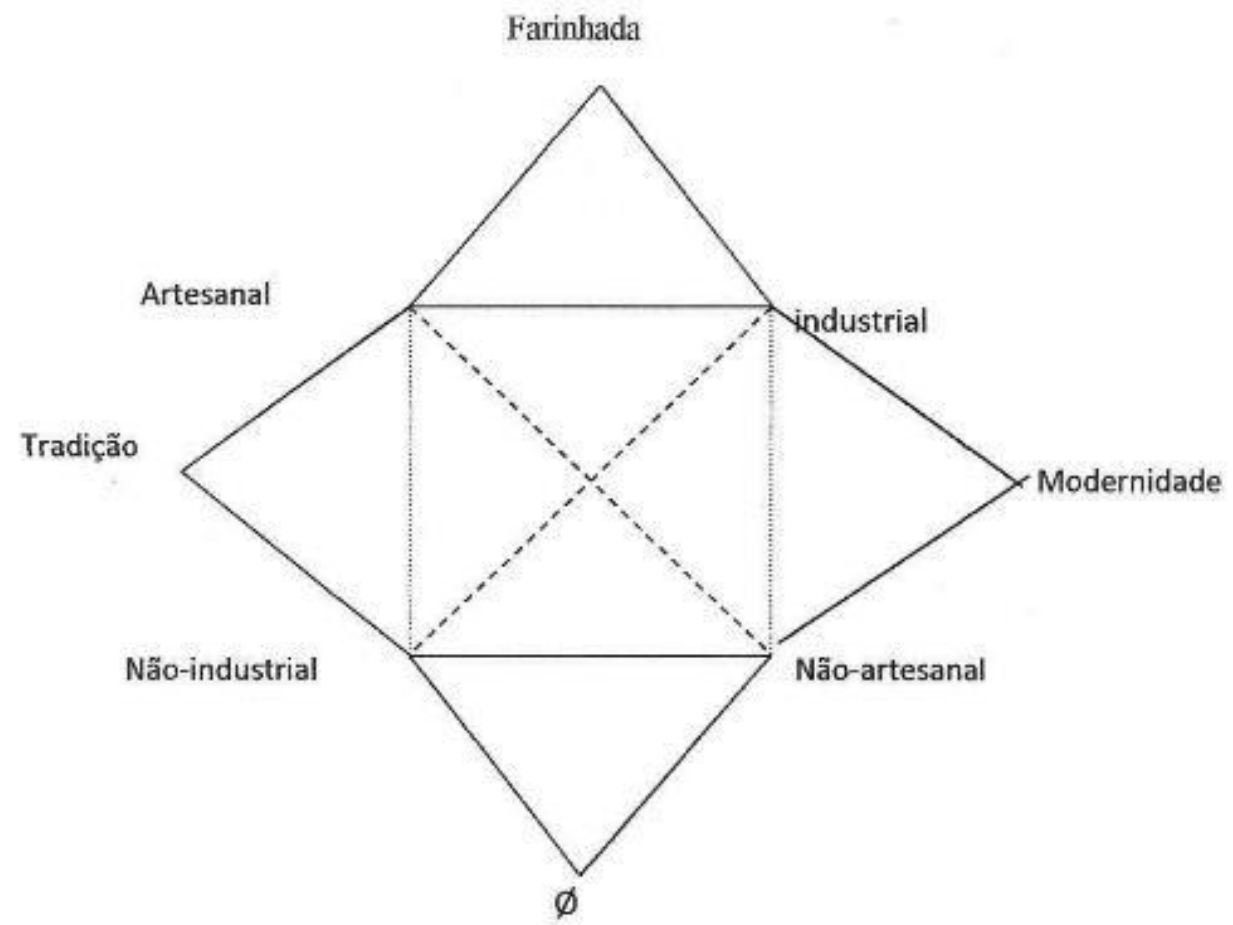

A partir desse octógono, notamos que a cultura apresentada na xilogravura em análise pode ser descrita como artesanal, representada pelo modo de fazer tradicional, coletivo e manual da confecção da farinha, onde todos participam das atividades e são beneficiados com a colheita. Já a cultura da indústria é figurativizada pelo trabalho moderno, isolado e com presença de motores e/ou máquinas elétricas, onde apenas o proprietário (empresário) detém o lucro e, muitas vezes, explora a mão de obra dos trabalhadores.

O título da obra, a farinhada, remete aos costumes tradicionais interioranos, quando a farinhada era motivo de festa. Este vocábulo, definido pelo artigo "a", indica que não é qualquer evento, pois se trata de um acontecimento de poderosa longevidade na tradição cultural popular nordestina, que porta um discurso festivo com banquetes de comidas (derivadas da mandioca), bebidas, estendendo-se pelas sessões de recital e contações de histórias, cantorias, piadas, coco de embolada, forró ${ }^{6}$, adentrando-se nas noites. Nesse amplo espaço, casa de farinha, as famílias solidárias da vizinhança, que trabalham por cortesia nesse ambiente, são compensadas pela reciprocidade da boa vizinhança, assim como, durante o trabalho, pelo espírito cooperativo com que ajudam

\footnotetext{
${ }^{6}$ Há casos em que não há instrumentos musicais, mas nem por isso as pessoas ficam sem dançar. Na base do improviso, fazem ritmo e acabam dançando, ritmados por cantos, assobios e estalos dos dedos, intercalados com as batidas contra o peito, batidas nas cadeiras, mesas, latas etc. Tudo isso estimulado por cachaça, vinho, café e delícias feitas a partir da mandioca.
} 
manualmente na produção da farinha. As famílias, solidariamente, comparecem a esse evento e prestam serviço em quaisquer das etapas que melhor se ajustem às habilidades de cada um. Dessa forma, a farinhada, que também se chama serão, torna-se um ato de representação da cultura que partilha o melhor que cada pessoa ou família tem a oferecer a partir de seus próprios esforços etc.,

\section{REFERÊNCIAS}

BATISTA, Maria de Fátima Barbosa de Mesquita. A significação como função semiótica. Graphos: Revista da Pós-Graduação em Letras, João Pessoa: Idéia, v. V, n.1, 2000.

O discurso semiótico. In: ALVES, E. F.; BATISTA, M. de F. B. de M; CHRISTIANO, M. E. A. (Org.). Linguagem em foco. João Pessoa: Idéia, 2001.

Os discursos etnoliterários: o fazer intersubjetivo e a produção do saber. In: Acta Semiótica et Linguística. João Pessoa-PB, v.18, nº 2, 2013.

LYRA, Yara Macedo. A linguagem da casa de farinha. Dissertação (Mestrado em Letras). João Pessoa: 1979 - Programa de Pós-graduação em Letras, Universidade Federal da Paraíba, UFPB.

PAIS, Cidmar Teodoro. Sociossemiótica, semiótica da cultura e processo histórico: liberdade, civilização e desenvolvimento. In: V Encontro Nacional da ANAPOLL.Anais. Porto Alegre: 1991.

Elementos para uma tipologia dos sistemas semióticos. Revista Brasileira de Lingüística. SBPC, v.6., n.1, São Paulo: 1992.

Texto, discurso e universo de discurso. Revista Brasileira de Lingüística. Vol. VI. São Paulo: Plêiade, n.1, ano 8, 1995.

Comunicação apresentada no congresso internacional de Literatura de Cordel. João Pessoa: Fundação casa de José Américo, 2005.

Considerações sobre a semiótica das culturas, uma ciência da interpretação: inserção cultural, transcodificações, transculturais. In: Acta Semiótica et Linguística. João Pessoa-PB, v.14, nº 1, 2009.

PIETROFORTE, Antonio Vicente. Semiótica visual: os percursos do olhar. São Paulo: Contexto, 2004.

RASTIER, François. Ação e sentido por uma semiótica das culturas. Tradução: Maria de Fátima Barbosa de Mesquita Batista. João Pessoa: Ideia/Editora Universitária, 2010.

Conecer y Significar. Tradução: Maria de Fátima Barbosa de Mesquita

Batista. In: Acta Semiótica et Linguística. João Pessoa-PB, v. 17, nº 1, 2012. 
ANEXO

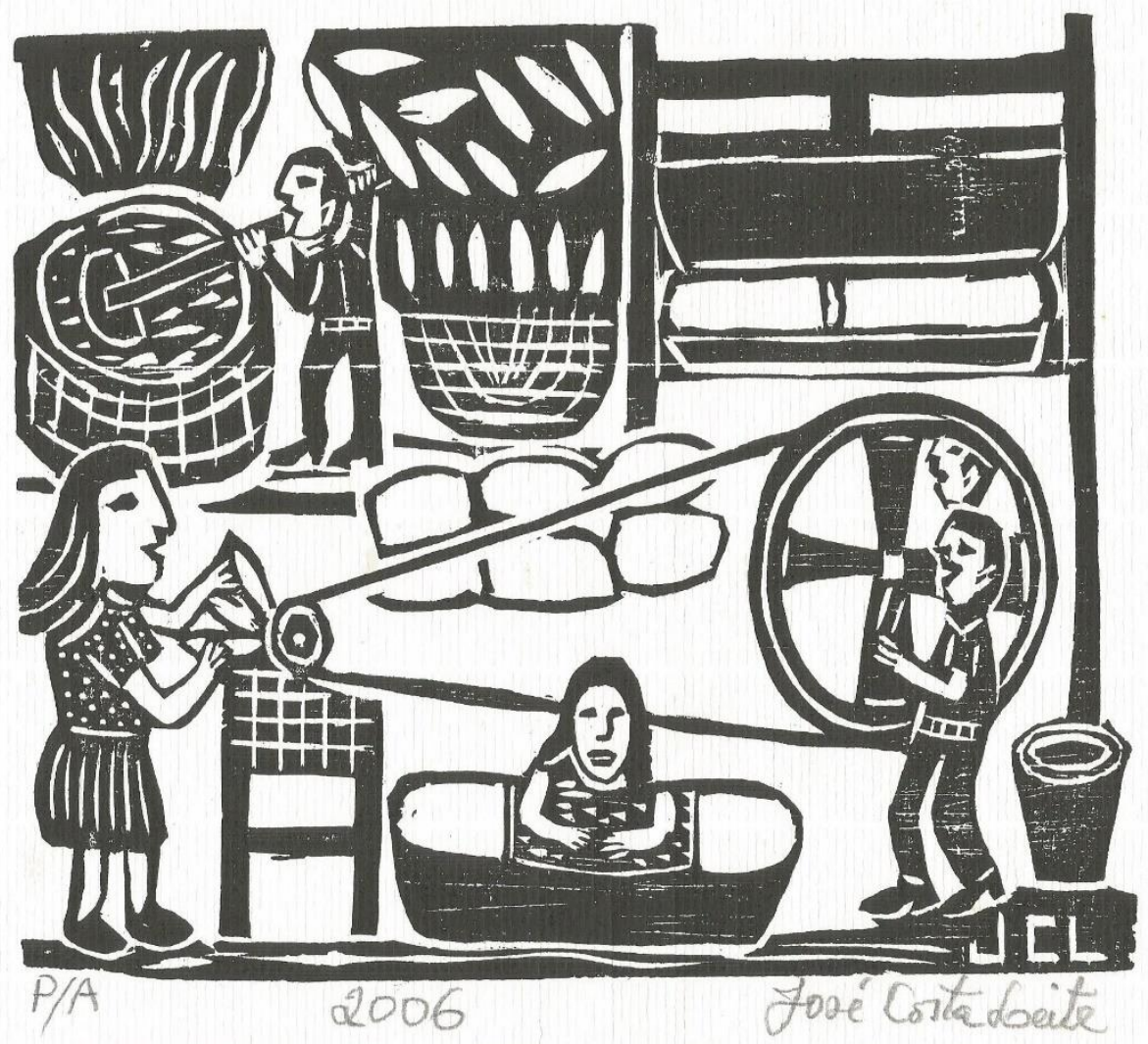

